\title{
Pemanfaatan Media Sosial Sebagai Media Promosi Dalam Pemasaran Produk Pada Koperasi Tahu Dan Tempe
}

\author{
Diana Novita $^{1}$, Agus Herwanto ${ }^{2}$, Meiyanti Nurchaerani ${ }^{3}$ \\ 1,2,3Universitas Esa Unggul \\ E-mail : 'ㄹiananovita306@gmail.com, ${ }^{2}$ aerwanto@gmail.com. ${ }^{3}$ meiy1405@gmail.com
}

\section{ARTICLE INFO}

Keywords:

Tofu,

Tempeh,

Crafters,

Social Media,

Facebook,

Instagram,

Promotion,

Marketing,

Tofu And Tempeh

Craftsmen,

Social Media Utilization,

Media Promotion

\section{ABSTRACT}

Marketing is a social and managerial process that makes individuals / groups get what they need and want by creating, offering and exchanging valuable products to other parties. Marketing involves many different activities that add value to the product when the product moves through the system. The current marketing system that is becoming a new trend is the online marketing system. With the emergence of a new era in the field of marketing which is referred to as the digital marfketing era, we entrepreneurs must consider various online media to be used in determining the company's strategic planning. One of the media intended is social media. Social media that is widely used by everyone and is quite popular in Indonesia today is Facebook and Instagram. Indonesia is one country with a high number of Facebook users, certainly has a great opportunity and opportunity to use social media as part of strategic marketing planning. Marketing through online media has many great advantages, one of which is that the costs incurred are relatively cheaper compared to other media in carrying out product promotion activities. In this paper, we discuss the promotion process for tofu and tempeh entrepreneurs in Indonesia. As we know, tofu and tempeh are one of the foods that can be categorized as a companion to the staple food of the Indonesian people. This soy-based food is very popular with all levels of society in Indonesia. However, tempeh and tofu are still categorized as food for the lower class. Meanwhile, we still import raw materials to get tofu and tempeh from abroad. The irony is that sounds, but, that's what happens now. The lack of knowledge of the tofu and tempeh artisans is what makes this commodity not glimpsed by circles other than the middle and lower classes. Therefore, we must educate the artisans of tofu and tempeh and teach them to know the tofu and tempeh globally. Increased knowledge and utilization of social media, one way to help boost the marketing of tofu and tempeh

\section{PENDAhULUAN}

Awal tahun 2000 adalah awal bagi bangsa Indonesia mengenal dunia usaha melalui media online. Maraknya marketplace saat itu hingga kini, menjadikan perubahan tren pemasaran yang terjadi di masyarakat Indonesia. Toko - toko online mulai tumbuh dan terus berkembang. Walaupun banyaknya kejahatan - kejahatan yang terjadi, tetapi tidak meredupkan minat masyarakat untuk melakukan transaksi secara online. Karena hal inilah, maka banyak media - media sosial yang mulai menambahkan fitur bisnis di dalam aplikasinya. Salah satu media sosial yang paling banyak penggunanya di Indonesia saat ini adalah Facebook dan Instagram. Indonesia sebagai salah satu negara dengan jumlah pengguna media sosial tertinggi saat ini, menjadikan Indonesia merupakan pangsa pasar yang sangat menjanjikan bagi kalangan usahawan. Banyak para pengusaha menjadikan media sosial yang mereka miliki sebagai sarana untuk menjaring konsumen melalui promosi yang gencar di media sosial ini. Selain sebagai media promosi, media sosial juga kerap dijadikan ajang pendekatan kepada calon customer ataupun customer dari suatu produk. Media sosial menjadi tren pilihan para usahawan karena lebih praktis dan tidak memakan banyak biaya untuk promosinya. Penjual dan pembeli pun bisa langsung berinteraksi saat itu juga. Cakupan media sosial jauh lebih luas daripada media televisi ataupun majalah atau koran. Bahkan mungkin sudah banyak usahawan yang mulai beralih dari media tersebut dan menggunakan media sosial karena relatif biaya promosi yang dikeluarkan, relatif jauh lebih kecil jika dibandingkan media televisi atau majalah ataupun koran. Selain masalah biaya, 
kelebihan lainnya dari menggunakan media sosial adalah cakupan yang luas, pengguna banyak, tidak mengenal batas ruang dan waktu, serta dapat dibuka terus menerus.

Koperasi sebagai wadah bagi para penghasil pangan di Indonesia merupakan suatu tempat bergantung para anggotanya. Koperasi juga memiliki peran penting dalam membantu peningkatan kesejahteraan hidup para anggotanya. Dengan adanya koperasi, diharapkan kesejahteraan anggota dan para calon anggota dalam hal ini adalah para petani penghasil pangan di seluruh wilayah Indonesia sangatlah diharapkan. Tetapi, seiring berkembangnya zaman, kemajuan teknologi tak lagi bisa dihindari. Mobilisasi masyarakat yang terus berubah, menjadi dilema tersendiri bagi kalangan penghasil pangan ini. Salah satunya adalah para penghasil tahu dan tempe. Seperti kita ketaui, tahu dan tempe merupakan bahan makanan yang cukup murah dan diminati masyarakat untuk dikonsumsi. Tetapi, bentuk dan rasa tempe yang hampir tidak banyak berubah dari waktu ke waktu menjadikan bahan makanan tersebut termasuk dalam golongan bahan makanan kelas bawah. Jika saja para penghasil tahu dan tempe mau mengexsplore lebh jauh mengenai produk ini, tentunya akan memberikan kemudahan dalam pemasarannya. Tetapi saat ini, para penghasil tahu dan tempe menghadapi suatu kondisi yang cukup lemah dikarenakan bahan baku untuk menghasilkan tahu dan tempe masihlah diimport.

Oleh karena banyaknya masalah yang dihadapi oleh para penghasil tahu dan tempe, maka kami mencoba untuk merangkumnya dalam sebuah penelitian dengan judul : PEMANFAATAN MEDIA SOSIAL SEBAGAI MEDIA PROMOSI DALAM PEMASARAN PRODUK PADA KOPERASI TAHU DAN TEMPE. Di dalam riset ini kami mencoba untuk memberikan sedikit ulasan bagaimana memanfaatkan media sosial sebagai sarana untuk berpromosi.

\section{METODE}

Desain penelitian yang digunakan adalah penelitian deskriptif atau yang biasa di sebut sebagai penelitian taksonomi. Penelitian taksonomi adalah suatu penelitian untuk mengexplorasi fenomena atau kenyataan sosial melalui suatu deskripsi sejumlah variable yang berkenaan dengan masalah dan unit yang akan diteliti. Penelitian deskriptif menggunakan data kuesioner dan tidak melakukan ujihipotesa serta tidak dimaksudkan untuk membangun dan mengembangkan suatu perbendaharaan teori. Dalam pengolahan data dan analisis data, lazimnya menggunakan pengolahan statistik yang bersifat deskriptif. Dengan metode deskriptif ini, dibuatlah suau deskrips secara sistematis, fraktual dan akuat dengan mengenai kondisi cara pemanfaatan.

Di dalam penelitian ini kami menggunakan metode deskriptif analisis dengan bantuan sebuah kuesionar yang kami olah sehingga menghasilkan data yang kami butuhkan. Adapun kuesioner yang kami ambil dari responden sejumlah 25 orang dengan jumlah pertanyaan 49 buah. Adapun inti dari pertanyaan pertanyaan yang termuat di dalam kuesioner adalah pertanyaan - pertanyaan yang berhubungan dengan keseharian responden dalam menggunakan media sosial tersebut. Responden yang kami ambil adalah semua anggota koperasi di koperasi tahu dan tempe tersebut.

\section{Penentuan Objek Penelitian dan Responden / Sampel}

1. Penentuan objek penelitian pada koperasi tahu dan tempe.

2. Penentuan objek penelitian juga mencakup kepada pengguna dari media sosial dalam hal ini adalah facebook.

\section{Pengumpulan Data dan Observasi Lapangan}

Metode pengumpulan data di akukan secara langsung pada:

1. Model transaksi di koperasi tahu dan tempe sebagai riset pendahuluan.

2. Anggota koperasi sebagai responden kuisioner.

3. Para anggota koperasi sebagai pemegang pelaksanaan transaksi bisnis secara manual sebagai responden wawancara dan kuisioner.

\section{Lokasi Penelitian}

Lokasi penelitian dipusatkan di Koperasi tahu dan tempe yang berada di wilayah Jakarta. 


\section{Tahapan Penelitian}

Adapun teknik digunakan dalam penelitian ini adalah:

1. Studi literature

Studi literature dilakukan dengan cara mengumpulkan dan mempelajari segala macam informasi yang berhubungan dengan pemanfaatan media sosial dan juga mengenai koperasi.

2. Pengumpulan data kuisioner

Pengumpulan data dilakukan dengan membagikan kuisioner kepada para responden serta wawancara kepada anggota koperasi terhadap hasil kuisioner.

3. Pengolahan data

Pengolahan data dilakukan terhadap hasil kuisioner yaitu dengan memberikan bobot terhadap kriteria penilaian pada setiap kategori, kemudian mengalikan dengan banyaknya responden yang memilih kriteria tersebut. Prosentase pada setiap kategori didapatkan dengan mencari bobot terbesar dibagi dengan total responden.

\section{HASIL DAN PEMBAHASAN}

Kuisioner dilakukan terhadap 25 responden yang berada di wilayah Jakarta, dimana responden terdiri dari laki-laki dan perempuan, berusia 30-45 tahun, berlatar pendidikan SMP / sederajat hingga perguruan tinggi, bidang pekerjaan pengrajin tahu dan tempe dengan aspek yang dianalisa meliputi 5 (lima) hal, yaitu tangible, reliability, responsif, assurance, dan emphaty. Selain kuisioner, juga dilakukan survey dan wawancara kepada pihak koperasi untuk mengetahui respon terhadap hasil penilaian responden terkait dengan pemanfaatan media sosial untuk usaha mereka. Berdasarkan hasil kuisioner dan survey serta wawancara yang dilakukan didapatkan hasil sebagaimana di bawah ini.

Untuk mengevaluasi tingkat kepuasan anggota koperasi terhadap pemanfaatan media sosail sebagai sarana pemasaran produk mereka, penilaian dilakukan dengan memberikan bobot terhadap masing-masing kriteria dengan bobot penilaian sebagai berikut:

$$
\begin{aligned}
& 1=\text { sangat kecewa } \\
& 2 \text { = kecewa } \\
& 3 \text { = cukup } \\
& 4=\text { puas } \\
& 5=\text { sangat puas }
\end{aligned}
$$

Dara pemberian bobot tersebut, maka didapatlah grafik dibawah ini yang mengetengahkan 5 (lima) aspek tersebut.

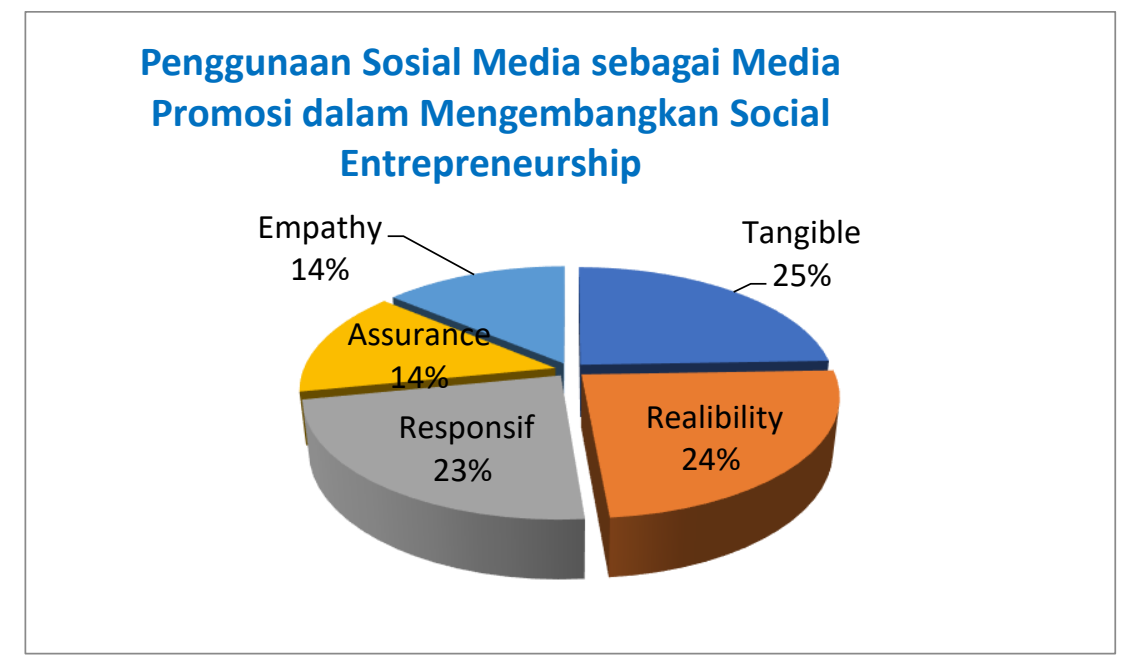

Gambar 1. Hasil penghitungan kuesioner. 
Pada grafik diatas, dapat dilihat bahwasannya setiap anggota koperasi belum memiliki tingkat pemahaman yang memadai untuk menggunakan media sosial sebagai sarana promosi produk - produk mereka. Minimnya pengetahuan tentang teknologi terkini merupakan salah satu kendala yang cukup signifikan dalam penggunaan media sosial tersebut. Untuk mengetahui respon dari pihak koperasi terhadap hasil penilaian responden terkait pemanfaatan media sosial. Wawancara yang dilakukan meliputi 5 (aspek) yaitu tangible, realibility, responsif, assurance dan emphaty.

Karena tingkat pemahaman dan kemampuan menggunakan media sosial, maka akan sulit bagi mereka untuk ikut berkompetisi dengan usaha sejenis. Olkh karena itulah, maka dibutuhkan banyak sekali pelatihan bagi seluruh anggota koperasi ini agar bisa ikut bersaing di dalam pasar digital saat ini. Mereka sudah harus mulai menyiapkan wawasan, kemampuan personal dan branding bagi produk - produk mereka sendiri. Semua proses menuju promsi melalui media sosial, kita tidak hanya memikirkan konten promosi saja, melainkan uga harus menyiapkan kualitas produk agar bisa bersaing. Mulai dari bagaimana menjadikan tempe dan tahu ini menjadi produk yang tidak mudah rusak, mendesign packing yang baik agar menarik konsumen, menghitung modal pokok produksi hingga pada akhirnya mampu bersaing di pasar digital.

\section{PENUTUP}

Untuk mengetahui sejauh mana tingkat pemahaman akan media sosial yang mereka gunakan, dilakukan analisa data yang diperoleh berdasarkan hasil kuesioner dari 25 responden dengan berbagai jenis kelamin, usia dan pekerjaan yang berada di wilayah Jakarta, serta hasil wawancara dengan 4 personil pengurus koperasi. Aspek yang dianalisa meliputi tangible, reliability, responsif, assurance, dan emphaty.

1. Pada aspek tangible yang meliputi pemahaman, penggunaan media sosial, menunjukan $25 \%$ responden merasa memahami dan memanfaatkannya.

2. Pada aspek reliability yang meliputi kemudahan akses, kemudahan penggunaan, menunjukan $24 \%$ responden merasa mampu menggunakannya.

3. Pada aspek responsive yang meliputi aktivitas memposting sesuatu, menunjukan $23 \%$ responden merasa cukup puas bahkan puas dengan hal - hal yang mereka bagiakan di media sosial mereka.

4. Pada aspek assurcane yang meliputi gangguan pada saat menggunakan medi sosial, menunjukan $14 \%$ merasa cukup terganggu saat menggunakannya.

5. Pada aspek emphaty yang meliputi perhatian terhadap individu, menunjukan $14 \%$ responden merasa cukup puas bahkan puas dengan emphaty saat memanfaatkan media sosial tersebut.

Untuk memaksimalkan proses pemanfaatan media sosial, harus didasari oleh pengetahuan yang cukup agar tidak salah sasaran saat mempublikasikan konten promosi di media sosial. Selin itu pula, dibutuhkan kualitas produk yang mumpuni agar produk yang ditawarkan tidak mendapatkan komplen dari konsumen. Masih luasnya pasar digital saat ini harusnya mampu memberikan peluang bagi para pengrajin tahu dan tempe ini. Para pengrajin haus mampu juga, enciptakan bentuk olahan baru agar terus berkembang dan berinovasi sehingga menimbulkan ketertarika konsumen untuk membelinya.

\section{DAFTAR PUSTAKA}

Dillon, William, R., \& Goldstein, Matthew. (1984). Multyvariate Analysis, Methods and Applications. New York.

Gary Growth - Marnat. (2009). Handbook of Psychological Assessment. Yogyakarta: Pustaka Pelajar.

Gosh S.1998, Making Business Sense of The Internet Harvard Business Review, March - April, pp 126-134.

Hamill J and Gregory. K. (1997). Internet Marketing in The Internationalization of UK Smes, Journal of Marketing Management, Vol.13, pp. 9-28.

Hakim, Abdul. (2001). Statistika Deskriptif untuk Ekonomi dan Bisnis. Yogyakarta. 